\title{
Apostillas en torno a dos novelas mexicanas recientes
}

Regina Landa, Marinno Azuela.-México, Ediciones Botas, 1939.

E1 doctor Azuela es el novelista mexicano actual que más amplia difusión ha alcanzado fuera de México y aquel de quien con más frecuencia se ocupa la crítica literaria de nuestra América. Desdichadamente se le conoce sólo como al autor de Las de abajo, pues son muy escasos los críticos que han leído su obra total.

La labor del doctor Azuela que más fama le ha valido es la que tiene relación con el ciclo revolucionario 1910-1920. Es, sin duda, la más interesante y de mayor mérito. Aparte alguna incursión al campo de la novela histórica como Pedro $\mathrm{Mo}$ reno el insurgente y al semihistórico como Precursores, casi la totalidad de su producción tiene como tema el devenir revolucionario y la postrevolución, es decir, la revolución hecha gobierno. De ahí que la novela de tal autor tenga el valor de un documento social para el estudio y conocimiento de este periodo de treinta años transcurrido desde la aparición de Mala yerba ( I909) hasta Regina Landa. Son ya más de veinte obras las 
que el autor lleva publicadas sobre la vida mexicana contemporánea, que él conoce bien por haberla surrido. Cuando historiadores y sociólogos de futuras generaciones quieran analizar este volcánico período de la historia de México, tendrán que consultar la producción novelística de tan modesto galeno como el más auténtico retrato que del decénio trágico y los veinte años que lo sucedieron dejó la generación que hizo la revolución.

No creo equivocarme al afirmar que la característica esencial de la obra toda del doctor Azuela es su acentuada propensión satírica. Esta tendencia es ya evidente en Mala yerba, su prinera novela bien calibrada. Desde entonces, la nota satírica cobra cada día mayor importancia hasta convertirse en las íltimas obras - El camarada Pantoja (1937), San Gabriel de Valdizias (1938) y la que nos ocupa- en propósito consciente $\mathrm{y}$ casi único. Lo que arites era secuela poco menos que inevitable dada la injusticia social imperante, háse convertido ahora en finalidad y objeto preconcebidos. El lector imparcial y enterado verá probablemente cási tanta injusticia hoy día como en la época de don Porfirio; por lo tanto, la sátira del autor está social y políticamente justificada. Visto el problema desde un ángulo distinto, no es posible, sin embargo, dejar de condenar el que la haya elevado a categoría de sistema. Me explicaré.

En Mala yerba, Los caciques, Las moscas, Los de abajo, Las tribulaciones de una familia decente y otras obras menores, la sátira era una resultante obligada, teniendo en cuenta la probidad intelectual y moral del autor y la sinceridad de su anhelo de renovación y mejoramiento económico y social de México; pero en aquellas obras la vena satírica se mantenía todavía en segundo término. Ahora, por el contrario, es el novelista el que ha pasado a segundo plano y el propósito satírico o docente a convertirse en raison d'être, principio y fin de su obra. ¿Resultado de esta evolución? Que el narrador genial que en el doctor Azuela había se ha inhibido, por así decirlo, y ha sido desplazado por el moralista. Lo que antes fuera impulso crea- 
dor, es ahora mero pretexto para enristrar a diestro y siniestro contra todo bicho viviente. La sinceridad de intenciones y lo justificado de su actitud son incontrovertibles; pero es innegable también que el gran novelista que en él había ha quedado supeditado al moralista y al reformador. Todo lo que estas tres últimas novelas ganan en eficacia didáctica para corregir al viciado político, lo pierden en valía artística. Son tres panfletos de gran fuerza satírica, mas su mérito literario como novelas es muy inferior al de sus cuadros revolucionarios. Diriase que el novelista ha muerto asesinado por el satírico que con él convivió durante treinta años. Es ésta una evolución análoga a la sufrida por otro intelectual revolucionario de la misma generación del doctor Azucla, José Vasconcelos, en quien se malogró in ensayista notable y sólo nos queda un desorbitado panfletista, resentido y megalómano, carente de la transida sinceridad evidente en el doctor Azuela.

¿Cómo explicar esta lamentable evolución que por desgracia parece indicar una definitiva orientación? No creo difícil la tarea. Por una parte, la conducta de los revolucionarios en el poder ha sido tan inepta y $\tan$ corrompida que han venido a hacer buenas las administraciones prerrevolucionarias. En la época de don Porfirio había funcionarios venales, pero también los había de una integridad a toda prueba, empezando por don Porfirio mismo, que tras más de treinta años en el poder, lo abandonó pobre, que no como los pelagatos que desde I920, habiendo ocupado un ministerio un par de años, salen millonarios. Y como don Porfirio, López Portillo y Rojas, don Justo Sierra, don Ezequiel A. Chávez y tantos otros. La nauseabunda conducta de la revolución hecha gobierno es la justificación y la causa que pudiéramos llamar objetiva de la obsesión satírica del gran novelista en los últimos años; pero además existen otros motivos más personales.

El doctor: Azuela pertenece a la primera promoción revolucionaria, a la maderista. Aquellos hombres, comenzando con 
el propio Madero, eran "evolucionistas", todos ellos aspiraban a restaurar el funcionamiento democrático y las libertades públicas siguiendo la pauta liberal-democrática que habían aprendido en los postulados de la revolución francesa. Su revolucionarismo era muy moderado y no rebasaba los límites de una renovación meramente política. El único leader de aquella generación que tuvo una visión clara de los problemas de México y encontró la fórmula salvadora fué el casi analfabeto Emiliano Zapata. Los demás aspiran a un cambio de régimen politico sin destruir la organización liberal-capitalista que ya por los años de 1910 a 1914 presentaba sintomas inequívocos de agotamiento en todo el mundo. Es decir, que ya en el momento en Madero y sus hombres surgían, el programa con que venían al poder era anacrónico $\mathrm{y}$, por consiguiente, inadecuado para resolver los problemas económicos y sociales del país. La tragedia de México no podía solucionarse con la panacea política del bienaventurado don Francisco I. Madero y sus utópicos consejeros. Zapata, al demandar la parcelación y devolución de las tierras al indio, había puesto el dedo sobre la llaga del latifundismo - mal de males de México y de toda América- y señalado la única pauta realmente revolucionaria y justiciera. Pero Madero y sus hombres, mejor intencionados que aptos, no se atrevieron a aplicar la fórmula salvadora y el sangriento conflicto de intereses entre los desposeidos y hambrientos y los potentados se hizo inevitable. Tras la bacanal de sangre, los nuevos revolucionarios victoriosos que habían prohijado el plan zapatista lo convirtieron en bandera política más que en realidad económica y a su sombra medraron. Asesinado Zapata, su programa sirvió a los pescadores de río revuelto, y en contubernio con otras ideologías foráneas se adulteró, sin haber sido nunca debidamente aplicado.

De la marejada revolucionaria de nuevo cuño, quedaron desplazados la mayor parte de los ideólogos maderistas como Luis Cabrera, Alberto J. Pani, Félix F. Palavicini, José Vasconce- 
los, Martín Luis Guzmán y tantos otros. Aparte la inmoralidad de todos los gobiernos revolucionarios, es innegable que la ideología que ha servido a los demagogos de las administraciones ulteriores es mucho más avanzada y radical que la de Madero y sus hombres, a cuyo grupo pertenece el doctor Azuela. De ahí que hoy casi todos ellos ocupen una posición conservadora $y$ hasta reaccionaria algunos de ellos, como Vasconcelos, por ejemplo. Políticos casi todos, al quedar preteridos del banquete oficial hánse convertido en los más duros censores y denostadores de los últimos regímenes revolticionarios.

El doctor Azuela no ha sido político militante nunca, ni ha aspirado a prebendas oficiales. Patriota y hombre honrado a carta cabal, no ha podido, sin embargo, sustraerse al pernicioso influjo de la política-y a vapulear la corrupción imperante, y a desenmascarar la traición a los principios revolucionarios perpetrada por los mismos que hicieron la revolución y ahora la usufructúan en provecho propio y en detrimento de la masa, ha consagrado su talento en los últimos años. Pero como dicho queda, el novelista se ha inhibido en favor del reformador $y$ del moralista. Así, don Mariano Azuela, tras de haber sido un novelista revolucionario -en la técnica más que en la ideología- que le marcó nuevos rumbos a la novela mexicana, vuelve al sendero ya recorrido por todos sus congéneres del siglo XIX y entra en el rumbo que a este género le señalara el primer novelista mexicano, José Joaquín Fernández de Lizardi : la proclividad moralizadora.

En El camarada Pantoja el doctor Azuela nos dió un cuadro que pudiéramos llamar de costumbres políticas, una aguafuerte de la corrupción imperante en las postrimerías del gobierno callista; en Regina Landa el autor arremete contra la ađdministración del general Cárdenas. ¿ Habrá que decir que no deja títere con cabeza? Ni siquiera Miguel Angel del Río, que al presentárnoslo parece gozar de las simpatías del autor, escapa a su iracundia, y de hombre refinado elegante y de talento, 
se nos transforma en el curso de la obra en un simulador egoísta y mediocre más odioso quizás que la mayoría de los demás personajillos que por estas páginas desfilan.

En su afán satírico, el doctor Azuela no sólo descuida ahora el dibujo de los caracteres, nunca muy firme en sus obras anteriores, sino que los unce al yugo de sus prejuicios. Todós los personajes de esta novela son como títeres de una farsa guignolesca en la que cada muñeco ejecuta sólo aquellos grotescos gestos que el manipulador -el autor- les obliga a realizar. Todo aquí está premeditado y condicionado por el propósito satírico. De ahí que los títeres que con nombre propio vemos moverse en estas páginas no adquieran personalidad ni relieves definidos. Son muñecos que el autor ha dibujado para demostrar su tesis y todos ellos aparecen en función de caricaturas de un periódico político de la oposición. A veces surge un carácter que amenaza con rebelarse contra la tiranía del autor y adquirir vida independiente y propia. Tales los casos del ya citado Miguel Angel y el del personaje apellidado de la Torre; pero el moralista que ha suplantado al novelista que en el doctor Azuela habia, pronto interviene para recortarles las alas y someterlas al común denominador.

De "reaccionario" oí que tildaban al doctor Azuela algunos de sus discípulos y admiradores de ayer y negadores de hoy, durante mi reciente estancia en México. La palabreja se ha desacreditado mucho allí en los últimos tiempos. Como si ello implicase un dicterio terrible o la consumación de un horrendo crimen, se acusa de "reaccionario" a todo el que en alguna forma censura la rapacidad o la ineptitud de los politicastros manidos que en México, como en casi toda nuestra América, desfalcan el tesoro público. No es mi intención confirmar ni negar la justicia de esta calificación; no me interesa tampoco averiguar si la realidad política mexicana justifica la actitud del autor, aunque concedo de buen grado que así sea. En estas notas volanderas se analiza la labor del novelista y no la actitud y la 
honradez del ciudadano. Lo que en uno es una virtud cívica respetabilísima y de mucha eficacia docente, puede convertirse en la más grave quiebra del novelista y del creador. $Y$ eso es, precisamente, lo que ha ocurrido en la evolución artística del doctor Azuela. Por eso el crítico imparcial no podrá menos que aplaudir aquella rebeldía y al mismo tiempo condenar esta supeditación del arte a otros fines y a propósitos que nada tienen que ver con la creación estética. Es éste un viejo tema todavía en disputa; pero el arte tiene sus fueros que no pueden vulnerarse impunemente. El doctor Azuela ha transgredido en sus últimas obras las fronteras artísticas y en el pecado lleva la penitencia, como reza el viejo refrán. ¿Volverá el gran narrador algún día sobre sus pasos? Lo dudamos. El, como Paul Bourget y otros muchos en Francia, Manuel Gálvez, Eduardo Barrios, Leopoldo Lugones y tantos otros antaño rebeldes en América, parece haber entrado en el sendero de las rectificaciones y del imperativo ético, sendero que jamás condujo al remanso de la auténtica inspiración y de la creación artística de gran aliento.

Huasteca, Gregorio López y Fuentes.-México, Ediciones Botas, 1939.

La novela nació en México - y tanto vale decir en América- bajo el signo del periodismo. José Joaquín Fernández de Lizardi fué el primer novelista y también el primer periodista profesional que por acá tuvimos. La escasa densidad de nuestra cultura, la precaria vida económica de nuestros países y las urgencias de la acción político-social son las causas de que muchos de nuestros hombres mejor dotados para la labor creadora, lo mismo en el ensayo que en la novela, en el cuento como en la poesía y la crítica literaria, hayan derivado hacia el periodis- 
mo. Así Sarmiento, Montalvo, Ricardo Palma, González Prada, Martí, Varona, Dario, Gutiérrez Nájera, Lugones, Sanín Cano y tantos otros hicieron de la prensa diaria un heraldo de ideas o un modus vivendi. Para la mayoría de estos hombres el periódico fué un vehículo de doctrinas renovadoras; para otros, como Darío y Gutiérrez Nájera, por ejemplo, fué casi su único medio de vida. Pero todos lo han ennoblecido con su genio. En las efímeras planas de nuestros diarios han aparecido, pues, muchas de nuestras obras de mayor vigor y perdurabilidad, desde el Facundo de Sarmiento y las páginas más nutridas y vibrantes de Montalvo y González Prada, hasta las prédicas apostólicas de Martí y los ensayos magistrales del gran don Baldomero Sanín Cano.

Concretándome a México y a la novela, diré que la influencia del periódico sobre este género es mayor quizás allí que en ningún otro país americano y se ha ido acentuando cada día más por razones políticas y económicas principalmente. Desde su fundador, Fernández de Lizardi, hasta Rafael F. Muñoz y Gregorio López y Fuentes, pasando por Luis Inclán, Manuel Payno, José Tomás de Cuéllar, Vicente Riva Palacio, Emilio Rabasa, José López Portillo y Rojas, Heriberto Frías, Federico Gamboa, Mariano Azuela y Martín Luis Guzmán, todos los principales novelistas mexicanos han sido o periodistas profesionales o a cllo han consagrado gran parte de su actividad intelectual. Otros, como el doctor Azuela, que han vivido alejados de la redacción y de la atmósfera de los grandes diarios, han publicado en ellos algunas de sus obras capitales y se han dejado influir por el carácter volandero y la intención transitoria de la faena periodística. Acentuando este centenario maridaje de la novela con el periodismo, notamos que muchas de las principales novelas de la revolución han aparecido originalmente en forma de folletón en los diarios mexicanos. Tales Los de abajo y Las tribulaciones de una familia decente, de Azuela; El águila y la serpiente, La sombra del caudillo y las Menorias de Pancho Villa, 
de Martín Luis Guzmán; ¡Vámonos con Pancho Villa!, de Rafael $F$. Muñoz, y otras varias.

No titubeo en afirmar, pues, que la novela mexicana adolece, más que la argentina o la chilena, pongamos por caso, de este carácter que lleva anexos todos los defectos de estilo y toda la superficialidad característica del reportaje informativo. Hechas todas las excepciones necesarias, todavía habrá que reconocer como ley fundamental de la novela mexicana esta proclividad. $\mathrm{Y}$ mientras no se saque el género del plano periodístico hacia el cual ha gravitado desde su inicio, la novela mexicana no adquirirá la potencialidad artística y el valor universal y permanente que toda obra de arte auténtico implica. Es necesario prescindir del impresionismo y la transitoriedad, de la anécdota y el propósito inmediato de propaganda o de lucro, para situar la novela en un plano superior de creación más objetiva y profunda. Quiere decir que es necesario bucear en el alma, en el ambiente y en el paisaje mexicanos para captarlos artísticamente con todas sus magníficas posibilidades estéticas. La patria, decía Martí, no es más que aquella porción del planeta y de la humanidad más próxima y mejor conocida porque en ella nos tocó nacer; y si el novelista mexicano logra dar forma artística a esa humanidad doliente que lo circunda y a ese paisaje físico y moral que lo aprisiona, habrá hecho obra tan universal y valedera como la que pueda hacerse desde París o Moscú. Como ha dicho un gran paisajista argentino en reciente ensayo:

"En realidad, siempre se persigue la aprehensión de lo universal en la novela: el alma del hombre y de lo creado. Sólo que esa aprehensión es a veces más eficaz cuando se ahonda en el terruño, en la aldea, en la campiña limitada, porque el conocimiento intenso de una área reducida, con su hombre, permite sondear la vida más profundamente y llegar así con mayor penetración psicológica a la raíz misma de lo universal, que es el alma del hombre y el misterio de lo creado... A lo tuniversal 
se llega tanto por lo regional como por lo cosmopolita, por la ciudad como por la aldea o por el campo. Y el tema de aquel carácter puede producir tan gran novela como el de éste. Ello depende del talento y del temperamento del novelador". ( I)

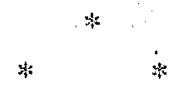

Gregorio López y Fuentes, como tantos otros congéneres compatriotas suyos, es periodista de profesión y novelista por la vocación y la aptitud. Todo lo que hasta aquí llevo dicho es aplicable al caso particular de este original narrador. Durante tres lustros, López y Fuentes ha derrochado su talento en el reportaje anónimo, primero; luego, en una sección semiliteraria y seminovelesca que se titulaba "La novela diaria de la vida real", publicada en el periódico "E1 Universal Gráfico"; más tarde escribió un cuento semanal para el suplemento dominical de dicho rotativo y, por último, ha dirigido "El Universal Gráfico" desde hace ya un lustro. Al margen de este bregar agotador, ha escrito seis novelas. La primera, Campamento, apareció en I93 I, y fué una gran revelación. Luego Tierra, Mi general, El indio, Arrieros y en el año en curso nos ha dado Huasteca. Si se tiene en cuenta que López y Fuentes apenas cuenta cuarenta y cinco años, se comprenderá cuánto puede esperar de él todavía la novela hispanoamericana.

En López y Fuentes culmina la evolución técnica de la novela mexicana que inicia el doctor Mariano Azuela, la cual ha venido a ser como el descubrimiento de una cuarta dimensión para este género. López y Fuentes ha llevado hasta sus últimas conclusiones el impersonalismo y el anonimato en la novela, características que por primera vez surgen en nuestra América con el autor de Los de abajo. Ya Campamento representó un progreso en esta dirección con respecto a todo lo que antes se había hecho para renoyar la técnica novelística. Tal renova- 
ción culmina - perfeccionándose- en El indio, universalmente proclamada como su mejor obra.

Como se ve, la producción novelesca toda de L.ópez y Fuentes surgió y se ha desarrollado a la sombra del periódico y esia indeseable asociación ha sido para él tan perniciosa como para la mayoría de sus colegas mexicanos. En pocos novelistas contemporáneos es tan flagrante este contubernio como en López y Fuentes; en ninguna otra novela suya es tan evidente este influjo como en la última. En cada una de sus obras anteriores, el gran narrador que en López y Fuentes alienta había hecho graves concesiones al periodista; pero todas ellas se redimen por el interés de los temas, por la habilidad en desarrollarlos y la audacia y novedad de la técnica, en la que se llega a la total supresión del argumento de los personajes y hasta de los nombres propios. Este era un procedimiento original y novedoso, que ningún otro autor de nuestra lengua se había atrevido a llevar tan lejos. Contra lo que pudiera pensarse, estas novelas sin enredo ni acción ni conflicto amoroso ni caracteres individualizados, resultan interesantísimas. El métier las salva y hasta las prestigia artísticamente. En todas ellas predomina el creador sobre el periodista, aunque la influencia de éste sea fácilmente perceptible.

Desdichadamente, en Huasteca se ha invertido el orden de los factores: el novelista ha abdicado subordinándose al periodista. De ahí que ésta sea la obra más deleznable que hasta hoy nos ha dado López y Fuentes. Nada en ella recuerda la agilidad narrativa y la excelente pintura de ambiente revolucionario que encontramos en Campamento; ni la integral comprensión del drama zapatista, de Tierra; ni la perfecta síntesis histórica que $E l$ indio comporta; ni siquiera aparece realzada con la rica vena folklórica y el inagotable refranero que ennoblecen a Arrieros. Todo en Huasteca es incoloro y mediocre. Los caracteres apenas están dibujados, el ambiente casi no existe, el argumento es magro y desmañado; el estilo, más desaliñado y 
pedestre que en ninguna de sus novelas previas. Todo aquí parece ser producto de la improvisación y hasta del desgano artístico, hecho a retazos, sin plan ni madurez. A ratos el lector cree estar leyendo el editorial de algún diario mexicano contemporáneo. Por ejemplo:

"Mucho se logrará el día que la muy necesaria labor social, sea deslindada de la política electiva. Pero este deslinde, más difícil que el reparto de un latifundio, sólo podrá hacerlo un legislador que no sea un político de oficio. Para ello es indispensable acabar con el fraude electoral, que el voto sea respetado, que las autoridades municipales no admitan ser cómplices en la confección de paquetes electorales y que la representación del país sea verdaderamente, en tales casos, un auténtico colegio electoral".

Nótese que no habla ningún personaje, sino el autor directamente. Y así páginas y más páginas, que parecen arrancadas de los artículos de fondo de "E1 Universal Gráfico". Otras veces son capítulos enteros compuestos con material "de relleno" : trozos de supuestos discursos de politicastros manidos, opiniones de charlatanes de café, etc. Tales capítulos me recuerdan esos periódicos que a última hora, y por falta de material, insertan pensamientos, poesías, charadas o acertijos tomados de almanaques o de cualquier parte, para no dejar un extremo de columna en blanco.

El autor no parece tener idea definida de lo que se propone hacer. El argumento es inconexo, los personajes intermitentes, el tema petrolero tratado sin vigor gramático ni digniclad artística. La técnica parece recordar lejanamente la empleada en otras novelas anteriores, principalmente en Tierra, pero mucho más desmañada ahora. Huásteca es lo que pudiéramos llamar una novela de ocasión, como esos poemas ripiosos, sin inspiración ni emotividad, hechos de encargo para conmemorar alguna 
efemérides o satisfacer la vanidad de alguna muchacha coleccionadora de autógrafos célebres. La cuestión petrolera es asunto palpitante en México y fuera de él, sobre todo desde que se proclamó el decreto de expropiación. López y Fuentes parece haber creído que sobre tema tan de actualidad podría hacerse una novela de fácil venta y acaso con posibilidades de ser traducida al inglés. $\mathrm{Y}$ ya sobre esta pista se lanzó a improvisar Huasteca. Pero no es ésta la novela que el petróleo puede darnos todavía. El tema está visto y tratado aquí "en periodista" y para aprisionarlo en toda su honda significación política, económica y social, es necesario olvidarse del impresionismo reportero y de la estridente actualidad del tema. Una visión más penetrante y más artística de la tragedia humana - lo económico no es más que un aspecto esencial de lo humano- que el petróleo ha significado para el pueblo mexicano, nos habría dado un drama palpitante de avaricia y sordidez, de intrigas y pugilatos internacionales, de dolor, de vicio, de miseria y de sangre proletarias. El tema se presta para una obra universal y profundamente humana y está pidiendo a gritos un creador genial que sepa aprovecharlo. En Huasteca parece que hubo el propósito de darnos esa fuerte visión; pero como dicho queda, el autor no logró plasmarla en realidad artística. Al contrario de las caucherías tropicales, la Huasteca espera todavía a un José Eustasio Rivera mexicano que nos dé esa otra vorágine del imperialismo petrolero.

\author{
Manuel Pedro González, \\ University of California at Los Angeles
}

(1).-Carlos B. Quiroga, La novela regional y la universal, prólogo a Liriolay, Buenos Aires, 1939. 
